\title{
A inserção e a consolidação do Brasil no sistema internacional por meio da Minustah
}

\author{
Brazil's Insertion and Consolidation in the International System through Minustah
}

\section{Pedro Chapaval Pimentel ${ }^{1}$}

Rafael Pons Reis ${ }^{2}$

\section{RESUMO}

Este artigo analisa a opção do Brasil por comandar a Missão de Paz para a Estabilização do Haiti (Minustah) como estratégia para sua inserção e consolidação como potência emergente no sistema internacional. Os resultados alcançados pela Minustah, o histórico brasileiro em missões de paz e a demanda por um assento permanente no Conselho de Segurança das Nações Unidas são explorados a partir da hipótese analítica relacionada ao uso de poderio militar como instrumento para fins de política externa.

Palavras-chave: Missões de paz; Minustah; Política externa brasileira.

\begin{abstract}
The article analyzes Brazil's choice to command the United Nations Stabilization Mission in Haiti (Minustah) as a strategy of insertion and consolidation as an emerging power in the international system. The Minustah's achievements, the Brazilian's historical involvement in peacekeeping missions, and its demand for a permanent seat in the United Nations Security Council are explored under the analytical hypothesis related to the use of military force as a tool to achieve foreign policy goals.
\end{abstract}

Keywords: Peacekeeping Operations; Minustah; Brazil Foreign Policy.

\section{INTRODUÇÃo}

O Brasil é um entusiasta da resolução pacífica de controvérsias. O seu envolvimento com missões de paz das Nações Unidas data da década de 1940 e, desde

\footnotetext{
1 Mestrando em Comunicação pela Universidade Federal do Paraná na linha Comunicação, Política e Atores Coletivos. Especialista em Relações Internacionais e Diplomacia pelo Centro Universitário Curitiba. Graduado em Comunicação Social pela Universidade Federal do Paraná e em Administração pela FAE Centro Universitário. Membro do Grupo de Pesquisa Comunicação Eleitoral da UFPR. Curitiba, Brasil.

2 Doutorando em Sociologia Política pela Universidade Federal de Santa Catarina. Mestre em Relações Internacionais pela Universidade Federal do Rio Grande do Sul. Especialista em Educação, Meio Ambiente e Desenvolvimento pela Universidade Federal do Paraná. Graduado em Relações Internacionais pela Universidade Tuiuti do Paraná. Professor do curso de Relações Internacionais do Centro Universitário Curitiba. Curitiba, Brasil.
} 
então, o país participou de 38 missões. Contudo, a partir dos anos 1990, verifica-se um padrão decisório da política externa brasileira. A fim de compreender esse padrão, optouse por analisar o envolvimento brasileiro com a Missão de Paz para a Estabilização do Haiti (Minustah).

A opção do Brasil por assumir o comando de uma missão do calibre da Minustah fornece indícios de mudanças no posicionamento diplomático brasileiro nos dois governos de Luiz Inácio Lula da Silva e no primeiro de Dilma Rousseff. Dessa maneira, lançamos mão de conceitos como Estado logístico, multilateralismo de reciprocidade, diplomacia solidária e não indiferença, a fim de encontrar relações entre a participação em missões de paz e a prática diplomática como atividades estratégicas para a consolidação do país como uma potência emergente de relevância.

A seção “O Brasil e as missões de paz das Nações Unidas” traça um breve histórico do envolvimento brasileiro em missões de paz e dá ênfase às missões mais significativas, seja para o sistema internacional, seja para o Brasil. A seção "Uma década de Minustah (2004-2014)" avalia os resultados logrados por meio da missão das Nações Unidas no Haiti. Finalmente, em "A política externa brasileira e a Minustah", avaliamos a estratégia de inserção e consolidação no sistema internacional empreendida pelo Brasil a partir da coordenação de matérias militares e diplomáticas.

\section{O BRASIL E AS MISSÕES DE PAZ DAS NAÇõES UNIDAS}

O envolvimento do Brasil em missões de paz da Organização das Nações Unidas (ONU) tem início já na primeira operação com a presença de militares, na década de 1940. Desde então, o país colaborou com o sistema de segurança internacional empreendido pela ONU tomando parte em 38 missões. Não obstante, o país enviou tropas somente para Suez, Angola, Moçambique, Timor-Leste, Líbano e Haiti (UN, 2015b, 2015d; UNIC Rio, 2015; PUFF, 2014).

Em 1948, o Brasil participou pela primeira vez de uma missão de paz da ONU com a alocação de três observadores militares voluntários na Comissão Especial das Nações Unidas nos Bálcãs (Unscob) (DEFESA, 2015). A missão foi estabelecida em 1947 e empregou militares para investigar acusações do envolvimento estrangeiro na Guerra Civil da Grécia (1946-49). 
A Primeira Força de Emergência das Nações Unidas (UNEF I) recebeu o primeiro envio de tropas brasileiras em 1956: um batalhão de infantaria de aproximadamente 530 homens conhecido como Batalhão de Suez. Em dez anos de existência, a UNEF I buscou estabilizar a região da península do Sinai e contou com cerca de 6.300 militares brasileiros, divididos em 20 contingentes semestrais. 0 Brasil esteve à frente do comando operacional dessa missão em 1964, 1965 e 1966 (DEFESA, 2015).

Se entre as décadas de 1940 e 1960 o Brasil se engajou em sete das 12 missões empreendidas pela ONU (58\%), entre 1970 e 1980 foram apenas duas participações num total de oito operações (25\%). A redução nas atividades em caráter militar internacional é reflexo da percepção de que as potências visavam às Nações Unidas para o congelamento do status quo. A opção por não ocupar assentos não permanentes no Conselho de Segurança (CS) e não se envolver em operações de paz demonstra o afastamento do Brasil do multilateralismo político nesse período (NASSER, 2012; BRACEY, 2011; CERVO, 2008).

O fim da Guerra Fria exigiu a resolução de conflitos resultantes de disputas internas por poder. A postura do governo brasileiro no cenário internacional também mudou devido à globalização, à redemocratização e às crises enfrentadas pela América Latina. A reinserção no sistema internacional pode ser traduzida pelo retorno do país ao CS como membro não permanente, após uma ausência de 24 anos, ou seja, houve um retorno ao multilateralismo. Para o Brasil, a participação em instituições internacionais traria melhoras na competitividade e no setor de defesa e também o acesso a novos mercados (BRACEY, 2011).

O Brasil acompanhou a evolução das missões de paz por meio da Operação das Nações Unidas no Congo (Onuc), na década de 1960, e das três missões de verificação das Nações Unidas em Angola (Unavem I, II e III), nas décadas de 1980 e 1990. No Congo, o Brasil realizou tarefas de cunho humanitário com a logística de suprimentos e medicamentos. Já em Angola, o envio de observadores militares criou, segundo Nasser (2012), um rationale da política externa brasileira para o emprego de militares em tais operações.

As operações em Angola, Moçambique, Timor-Leste e Haiti demonstram o empenho brasileiro em prestar auxílio a países com "herança histórica ou cultural - ou (com) aqueles em que as circunstâncias e o discurso diplomático permitiram tal 
associação" (NASSER, 2012, p. 215). Há uma ênfase em missões de caráter multidimensional, que visam ao desenvolvimento socioeconômico, ao fortalecimento de instituições políticas e à garantia dos direitos humanos. No Líbano, o envolvimento brasileiro ocorre desde 2011, com o comando naval da Força-Tarefa Marítima da Força Interina das Nações Unidas no Líbano (Unifil), sendo a primeira vez em que uma missão da ONU conta com uma força marítima (MARINHA, 2015).

A Minustah, cuja liderança está nas mãos de generais brasileiros desde 2004, é considerada o principal envolvimento brasileiro com missões de paz das Nações Unidas. Assim, Seitenfus (2014a) destaca quatro fatores que tornam essa missão singular: (1) é a primeira missão da ONU em que a América do Sul tem a maioria da tropa; (2) é a primeira vez que o Brasil comanda uma operação de paz internacional; (3) o contingente brasileiro no Haiti é o maior deslocado para fora das fronteiras nacionais desde 1945; e (4) a participação brasileira vai além da garantia de instauração de condições seguras para o desenvolvimento de um processo democrático.

Mesmo que a Minustah tenha adquirido relevância no cenário internacional, ainda restam dúvidas quanto à sua eficácia, uma vez que sua duração ultrapassa dez anos, desde que a Resolução 1.542 autorizou sua criação, em 2004. Hodiernamente, não há uma data que preveja o término e a retirada da missão e, além disso, desenvolveu-se uma interdependência entre a legitimação do governo nacional haitiano e a presença das tropas no país, fazendo com que um exista em função do outro.

\section{UMA DÉCADA DE MINUSTAH (2004-2014)}

Em 2014, a Minustah completou dez anos em meio a impasses políticos, debilidade das instituições governamentais, escassa infraestrutura e recorrentes desastres naturais. Contudo, as intervenções militares alóctones no Haiti têm início ainda na década de 1990, quando, após uma série de golpes militares, o governo provisório solicitou apoio para a realização de um processo eleitoral democrático, livre, justo e seguro. Desde a primeira eleição democrática, em 1990, sob a supervisão de observadores internacionais, o país recebeu sete operações de paz e se tornou cada vez mais dependente de forças militares estrangeiras (SEITENFUS, 2014a; UN, 2003). 
Em 2004, o Haiti foi considerado uma ameaça à segurança e à paz internacionais devido à eclosão de conflitos armados. Para restaurar um processo político pacífico e garantir o estabelecimento da ordem, o CS mobilizou e enviou a Força Interina Internacional (MIF), que após 90 dias foi substituída pela Minustah. 0 sustentáculo dessa missão foi pautado em três dimensões: 1) segurança e estabilidade; 2) processo político; e 3) direitos humanos (FAGANELLO, 2013; BRACEY, 2011; UN, 2003, 2004b). Desde então, foram mobilizadas tropas de 52 países e houve auxílio de diversas instituições internacionais, como a Comissão Econômica para a América Latina, o Banco Mundial, o Fundo Monetário Internacional e o Banco Interamericano de Desenvolvimento (UN, 2015c; SEITENFUS, 2014a).

O Haiti é o país mais pobre das Américas e a atuação da Minustah trouxe resultados positivos em termos econômicos. A figura 1 mostra que, enquanto em $2004 \mathrm{o}$ Produto Interno Bruto (PIB) logrou uma taxa de crescimento de -3,5\%, entre 2005 e 2007 houve um crescimento positivo em três anos consecutivos devido ao aporte de capital estrangeiro e ao impulso dado pelo setor terciário (RESERVE, 2013; IHSI).

FIGURA 1 - Crescimento do Produto Interno Bruto (PIB) haitiano entre os anos de 2004 e 2014.

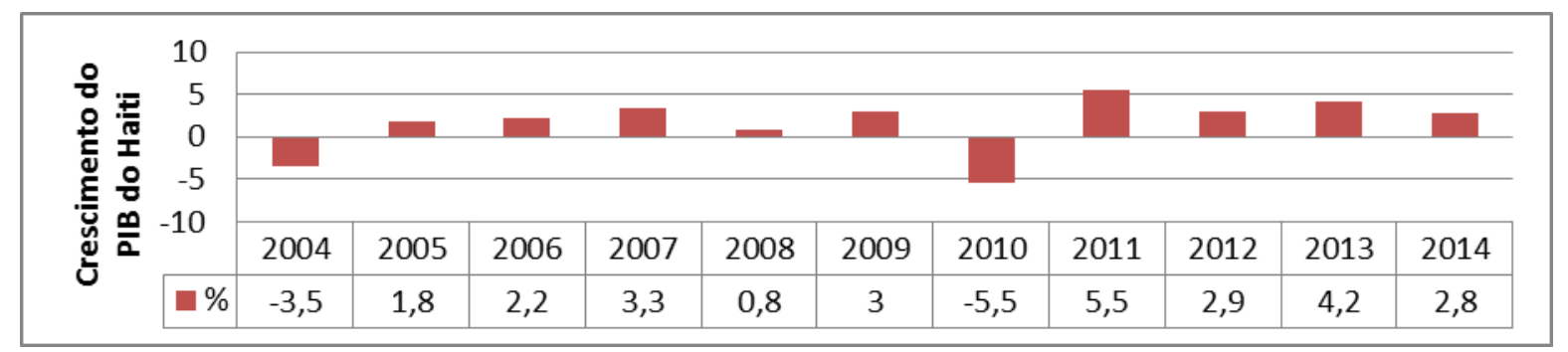

FONTE: adaptada de Institut Haïtien de Statistique et d'Informatique.

Em 2008, o país foi alvo de uma série de furacões que resultaram em milhares de desabrigados, em centenas de mortos e na perda da colheita de alimentos. 0 setor primário da economia foi o mais atingido, com uma redução de mais de $6 \%$ em seu valor agregado, causando uma súbita alta no custo de alimentos e combustíveis. (IHSI, 2010; MONTES; FELDMANN; PIRACÉS, 2009). O terremoto de 2010 trouxe prejuízos que ultrapassaram US\$ 7 bilhões, o equivalente a mais de 120\% do PIB haitiano no ano anterior (GOH, 2010). Estimam-se, como consequência direta, a morte de cerca de 300 mil pessoas e a destruição de 60\% dos prédios públicos (LFH, 2015). Para mitigar a situação, 
o CS aumentou o número de contingentes da missão em 2.000 militares e 2.180 policiais (UN, 2010a, 2010b).

Ainda em 2010, alastrou-se uma epidemia de cólera que em menos de um ano causou 439.846 contaminações e 6.309 mortes no Haiti (Fadisma, 2011). Em 2011, o aumento de $20,7 \%$ dos investimentos estrangeiros diretos e os empréstimos ao setor privado foram responsáveis pela relativa recuperação da economia (IHSI, 2011). Deu-se início ao Projeto 16/6, que auxiliou na criação de empregos e no aquecimento da economia local, pois o material de construção e a mão de obra eram oriundos das regiões mais atingidas pelos desastres naturais (PROJET 16/6, 2012).

Os furacões Isaac e Sandy atingiram o país em 2012 e fizeram com que o ano de 2013 fosse novamente de reconstrução. O PIB foi impulsionado pelo setor de construção com obras de infraestrutura do governo, como rodovias, prédios públicos e aeroportos. Contudo, mais da metade do orçamento anual haitiano era dependente de ajuda internacional (IHSI, 2013; UN, 2013a). A seca de 2014 destruiu milhares de hectares de plantações e matou outros milhares de cabeças de gado, e os prejuízos econômicos foram da ordem de US\$ 104 milhões no setor agropecuário, cerca de 23\% do PIB. 0 impacto na economia só não foi pior porque a indústria, os gastos do governo e o setor de serviços aumentaram 7,5\% e 3,7\%, respectivamente (IHSI, 2014, 2013).

A economia do Haiti se reflete no ambiente político, pois desde a primeira experiência eleitoral, em 1986, há uma permanente crise político-democrática. Seitenfus explica que, num país onde " $50 \%$ da população sobrevive abaixo da linha da miséria, o controle dos escassos recursos do Estado se constitui na única fonte de riqueza" (2014a, p. 73). Consequentemente, as intervenções militares empregadas no Haiti tiveram dentre seus objetivos assistirem a restauração de um governo democrático legítimo, a reorganização das forças armadas e o treinamento da força policial haitiana visando solucionar problemas de instabilidade política e segurança pública (FAGANELLO, 2013; BRACEY, 2011).

Há inúmeras dificuldades na aprovação de projetos de lei que beneficiem a população, pois o poder político serve como instrumento de representação institucional, em vez de solução para os conflitos. Esse é o caso dos programas sociais envolvidos no EDE PEP (Ajuda ao Povo), que, embora tenha gerado resultados positivos, não tinha critérios claros para a participação da população e as regiões de maior assistência 
coincidiam com aquelas de maior número de mobilizações contrárias ao governo de Michel Martely (RESERVE, 2013).

As suspeitas de fraude nas eleições de 2000, que elegeram como presidente JeanBertrand Aristide, levaram o país a um colapso institucional em 2004, com conflitos armados e violações de direitos humanos. 0 Parlamento deixou de funcionar, com o término do mandato de todos os deputados e de dois terços dos senadores, e Aristide renunciou ao cargo e deixou o país. Assim, o Haiti foi administrado por decretos pelo presidente interino Boniface Alexandre e pelo primeiro-ministro Gerard Latortue (SEITENFUS, 2014a; FAGANELLO, 2013; BRACEY, 2011; UN, 2004a; IPU, 2006).

Mesmo com o resguardo da comunidade internacional para a realização de eleições, desde a chegada da Minustah foram registrados inúmeros problemas, como adiamentos, fraudes, intimidações, protestos e violência devido à falta de segurança, de condições logísticas e de trabalhadores. Reserve (2013) explica que nem o governo, nem o sistema democrático haitiano sobreviveriam às dificuldades eleitorais sem o apoio da Minustah e da comunidade internacional.

Em 2005, deu-se início ao processo de cadastramento eleitoral com o registro de cerca de $70 \%$ da população apta a votar. Após quatro adiamentos, o primeiro turno para presidente, deputados e senadores foi realizado em fevereiro de 2006 e elegeu René Préval presidente e Jacques-Edouard Alex primeiro-ministro. No Legislativo, somente dois candidatos à Câmara dos Deputados foram eleitos no primeiro turno, e o segundo turno ocorreu com um mês de atraso. Com módica parcela de eleitores, foram eleitos 27 dos 30 senadores e 88 dos 99 deputados. As eleições para os assentos restantes foram concluídas somente no ano seguinte, juntamente com as eleições locais e municipais, que contaram com apenas 36\% dos eleitores (GS, 2011; IMMHE, 2007; IPU, 2006).

As eleições para o Senado, previstas para 2008, foram realizadas em 2009 e tiveram aproximadamente 78\% dos custos financiados por Canadá, Estados Unidos e União Europeia. A oposição boicotou o pleito e o primeiro turno contou com somente 11\% dos eleitores, pois o Conselho Eleitoral Provisório (CEP) havia impedido alguns candidatos da oposição de concorrer. Houve, ainda, problemas na entrega das células de identidade nacional, e os resultados de algumas zonas eleitorais foram invalidados pelo CEP. O segundo turno foi novamente marcado por boicotes, episódios de violência, urnas danificadas e tentativas de intimidação e de fraude. Alguns senadores rejeitaram os 
resultados e somente em setembro daquele ano os senadores foram empossados (SCR, 2015; IPU, 2010).

O sufrágio de 2010-2011 era reflexo do caos vivido no Haiti. Previsto para fevereiro de 2010, foi realizado somente em novembro, após decreto de Préval. Apesar do número recorde de candidatos (850 candidatos à Câmara dos Deputados, 95 para os 11 acentos do Senado e 19 para a Presidência), o pleito contou com apenas 22\% dos eleitores. Ele foi monitorado pela Comunidade do Caribe e por uma Missão de Observação Eleitoral da Organização dos Estados Americanos (OEA) e elegeu 22 deputados e quatro senadores. O segundo turno ocorreu somente em março de 2011, após recontagem de votos pela OEA, e elegeu os assentos restantes para o Senado e para a Câmara dos Deputados (IPU, 2015).

A chegada de Michel Martelly à Presidência gerou instabilidade, pois a oposição era maioria no Legislativo. Assim, os conflitos entre Executivo e Legislativo culminaram na prisão ilegal do deputado oposicionista Anel Bélizaire, em 2011, e na renúncia do primeiro-ministro Garry Conille, em 2012 (SCR, 2015; RESERVE, 2013). Ainda, o Senado permaneceu funcionando sem a terça parte cujo mandato expirou em 2012, e houve a criação de "agentes municipais" para substituir 130 prefeitos na mesma condição (GONZALEZ, 2014).

O sistema político se deteriorou quando, pelo quarto ano consecutivo, em 2014, o Haiti não conseguiu promover eleições. A supervisão do processo político por forças externas tornou-se condição sine quae non às transições democráticas e, mesmo assim, ocorreram diversas irregularidades (IPU, 2015, 2006; SCR, 2015; UN, 2011b, 2010c; MONTES; FELDMANN; PIRACÉS, 2009).

A classificação do Haiti no Índice de Estados Falidos (IEF), relatório que avalia indicadores sociais e é elaborado pela organização Fundo para a Paz, reflete os problemas do país. ${ }^{3}$ As posições mais altas nesse índice indicam a incapacidade do país de manter uma normalidade política, econômica e social. Como mostra a figura 2, a melhor posição alcançada pelo Haiti foi o $14^{\circ}$ lugar em 2008, um ano relativamente calmo em termos políticos devido à conclusão das eleições gerais em 2007. Já os anos de eleições gerais

\footnotetext{
${ }^{3} \mathrm{O}$ primeiro relatório do IEF foi divulgado apenas em 2005. 
(2006, 2009 e 2011) foram aqueles com as piores classificações do país. 0 pior ano, 2011, foi consequência do terremoto de 2010.

FIGURA 2 - Classificação do Haiti no Índice de Estados Falidos entre 2005 e 2014.

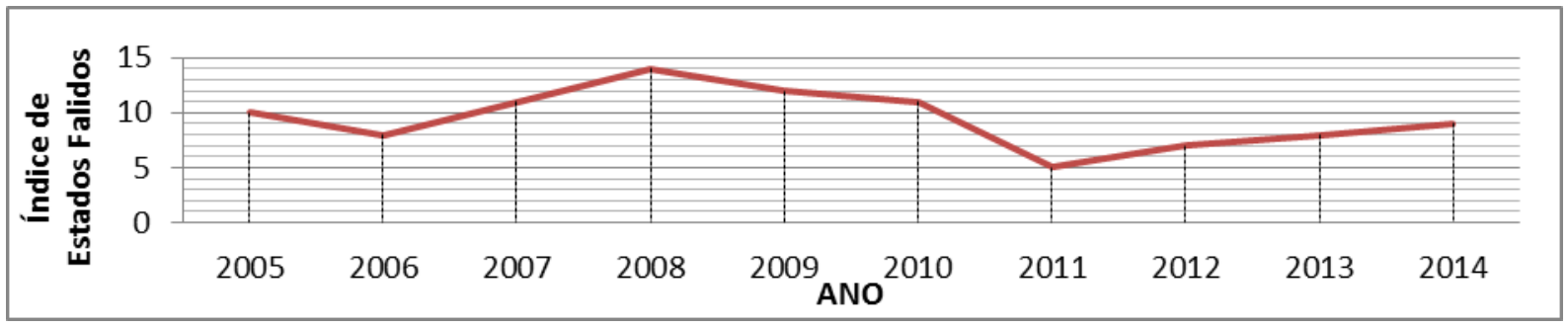

FONTE: adaptada de The Fund for Peace (FFP).

0 Índice de Desenvolvimento Humano (IDH), elaborado pelo Programa das Nações Unidas para o Desenvolvimento Humano (Pnud), apresenta o Haiti como único país das Américas com baixo desenvolvimento humano. Durante os dez primeiros anos da Minustah, o país passou da 153a para a 168ª posição (HDR, 2014, 2006). Assim como acontece com a economia haitiana, as catástrofes naturais e os problemas de cunho político prejudicaram a atuação da missão, fazendo com que ela existisse mais em função de contingências do que de mudança estrutural do país (figura 3).

FIGURA 3 - Classificação do Haiti no Índice de Desenvolvimento Humano entre 2004 e 2014.

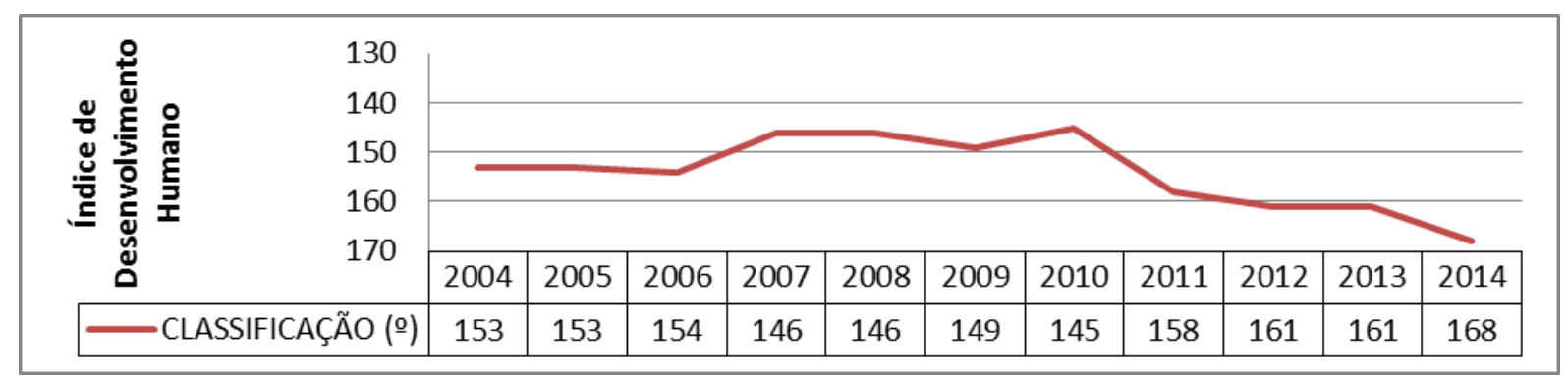

FONTE: elaboração própria a partir de dados do HDR.

Ao fim de 2014, cerca de 80 mil pessoas ainda viviam em 105 diferentes campos para desabrigados. Em comparação com 2010, esse número representa uma redução de 94\% no número de haitianos desabrigados e de 93\% na quantia de campos abertos e em funcionamento. No entanto, durante esse levantamento da Organização Internacional para as Migrações, nenhum campo foi fechado. Ainda, as Nações Unidas afirmaram que não havia perspectiva de uma solução durável para o caso (HRW, 2015; LANZONI, 2015). 
A existência de problemas estruturais como os débeis sistemas de distribuição de águas, de coleta de esgoto e de saúde perpetua a cólera e a diarreia. Os registros de cólera ultrapassaram 712 mil contaminações e 8,6 mil mortes em 2014. Entre os meses de janeiro e outubro foram cerca de 14 mil casos suspeitos e 132 mortes, uma redução de 69\% em comparação ao mesmo período do ano anterior. A resposta para mitigar esse surto limitou-se à identificação, descontaminação e subsequente proteção das fontes de água contaminadas (HRW, 2015; UN, 2014a, 2014c).

A introdução do Vibrio cholerae nos rios haitianos ocorreu com o lançamento de dejetos da base da Minustah em Mirebalais (ZANELLA; BERALDO, 2012). 0 problema foi agravado pelo imobilismo das entidades envolvidas com o país, que negaram a responsabilidade pela introdução da doença, cujo último caso registrado havia sido há aproximadamente cem anos. Seitenfus (2014a) destaca que o relatório publicado pela ONU em 2011 forneceu elementos que possibilitariam o estabelecimento de nexo causal entre a introdução da bactéria e a base da missão.

Entre 2007 e 2014 foram registrados 95 casos de exploração e abuso sexual envolvendo a Minustah (UN, 2015a). Em 2007, 103 soldados do Sri Lanka foram repatriados. Destes, três eram comandantes militares. Em 2011, outros cinco soldados, dessa vez uruguaios, foram repatriados e presos. Em 2012, houve a instalação de um tribunal militar paquistanês ad hoc que condenou dois policiais a um ano de prisão, a ser cumprida no país de origem (SCR, 2015; UN, 2015f; FAGANELLO, 2013).

O caso do ex-presidente Jean-Claude Baby Doc Duvalier, acusado de crimes contra o sistema financeiro e de violações de direitos humanos durante seu mandato, demonstrou a parcialidade do sistema judiciário, pois ele faleceu sem ao menos ser levado aos tribunais. 0 sistema carcerário permanecia superlotado, com prisões arbitrárias e preventivas que se prolongavam mais do que o necessário (HRW, 2015).

A segurança pública demonstrou-se frágil com os ataques a instalações das Nações Unidas em 2009, quando um grupo de ex-militares tomou prédios públicos e realizou patrulhas armadas em 2012. O trabalho conjunto entre Minustah e Polícia Nacional Haitiana (HNP), todavia, trouxe bons frutos com o desmantelamento e a prisão de gangues. A capacidade de atuação da HNP ainda era limitada, pois o efetivo policial disponível era menor do que a metade necessária (HRW, 2015; SCR, 2015; UN, 2014b; RESERVE, 2013). 
A partir de 2011, deu-se início à diminuição gradativa de contingentes da missão. Embora, em 2014, fosse contabilizado o menor número na história da Minustah, isso não representa uma tendência à retirada da Minustah do país, pois tal número é semelhante ao de 2004 (figura 4).

FIGURA 4 - Número de tropas (militares e policiais) em atuação no Haiti entre 2004 e 2014.

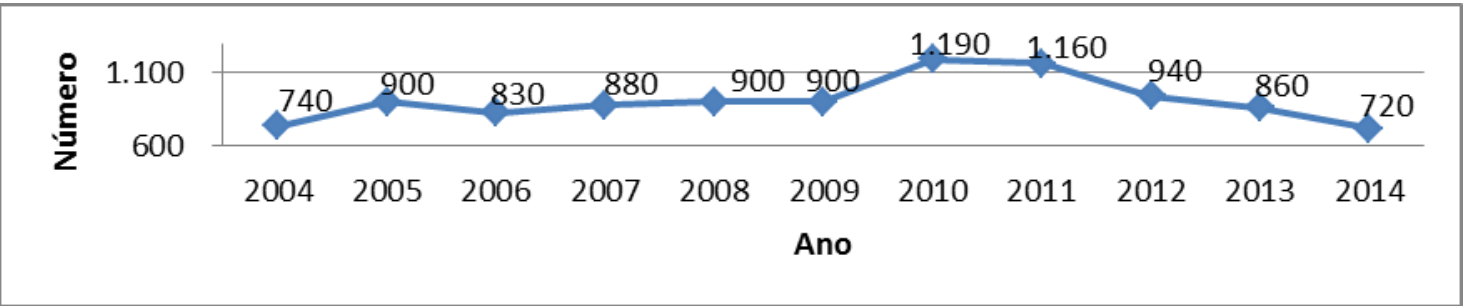

FONTE: elaboração própria a partir de dados de UN, 2015c.

É possível verificar que o Haiti vive uma espécie de ciclo em que a permanência da Minustah depende da legitimação do governo, que por sua vez é dependente do suporte da missão. Em outras palavras, há uma relação de ganhos mútuos entre as Nações Unidas e o governo haitiano. Essa questão pode ser estendida às motivações brasileiras em assumir o comando da missão. As operações de paz adquirem importância na identificação de aspectos da política externa brasileira, uma vez que é possível verificar a aspiração da diplomacia nacional a fazer do Brasil um país integrado ao sistema internacional como potência emergente.

\section{A POLÍTICA EXTERNA BRASILEIRA E A MINUSTAH}

O hiato de 14 anos entre o primeiro envolvimento do Brasil com o Haiti no campo das Nações Unidas, em 1990, com o Grupo de Observadores das Nações Unidas para a Verificação das Eleições no Haiti (Onuveh), e o retorno com a Minustah, em 2004, indica distintas estratégias de posicionamento e inserção no sistema internacional nesse período.

Durante os anos 1990, o Brasil só se envolveu na questão do Haiti quando o embaixador brasileiro João Augusto de Médicis esteve à frente do Onuveh como representante pessoal do secretário-geral da ONU. Naquela década, foram enviadas 
quatro missões de manutenção da paz para o Haiti, das quais o Brasil não participou. ${ }^{4}$ Destarte, quando o país teve direito a voto no CS, entre 1992 e 1994, ele não só não se absteve da votação que autorizava o envio de duas forças multinacionais lideradas pelos Estados Unidos como se opôs (SEITENFUS, 2014a; BORGES, 2011).

Em contrapartida, em 2004, o Brasil aceitou participar da missão no Haiti em meio a controvérsias, conforme explorado por Seitenfus (2014a), Bracey (2011) e Gauthier e Sousa (2006). Pela primeira vez o país aceitou comandar uma operação de paz baseada no capítulo VII, cuja resolução autoriza sanções e o uso da força pelas tropas (SOUZA NETO, 2012). Para Seitenfus (2014a), neste momento há uma mudança brusca no processo de tomada de decisão brasileira, pois o país não levou em consideração a tradição de rejeição do uso da força na resolução de conflitos.

Para justificar essa mudança de direção, a diplomacia brasileira utilizou-se de elementos encontrados na perspectiva mais humanista do presidente Lula da Silva, com destaque para os conceitos de diplomacia solidária e não indiferença (SEITENFUS, 2014a). A diplomacia solidária é uma ação coletiva internacional de países, geralmente em desenvolvimento, que, desprovidos de interesses materiais e/ou estratégicos, têm como única motivação o dever da consciência. Já a não indiferença se operacionaliza a partir da diplomacia solidária e ocorre por meio de países que demonstram prontidão em praticar solidariedade e assumir responsabilidades para com países que "sofrem em função de conflitos internos, carências de todas as ordens, repressão, falência do Estado, impossibilidade ou ausência de vontade deste de reduzir tais sofrimentos" (SEITENFUS; ZANELLA; MARQUES, 2007).

Se, por um lado, o Brasil justifica sua participação na Minustah com a perspectiva humanista de Lula da Silva, por outro é possível inferir a busca de interesses de inserção e consolidação no sistema internacional. Nogueira e Messari (2005) afirmam que é natural a ocorrência de articulações outrora inadmissíveis no cenário internacional, pois os Estados se encontram em um ambiente heterogêneo e almejam o cumprimento de seus próprios objetivos.

A cooperação ocorre quando determinados atores ajustam seu comportamento às preferências reais ou esperadas de outros atores por meio de um processo de

\footnotetext{
${ }^{4}$ United Nations Mission in Haiti (UNMIH - 1993-1996); United Nations Support Mission in Haiti (UNSMIH - 1996-1997); United Nations Transition Mission in Haiti (UNTMIH - 1997-1997); United Nations Civilian Police Mission in Haiti (MIPONUH - 1997-2000).
} 
coordenação política. Em suma, a cooperação intergovernamental ocorre quando determinadas políticas seguidas por um governo são entendidas por seus parceiros como facilitadoras da realização de seus próprios objetivos, como resultado de um processo de coordenação política (KEOHANE, 1984, p. 51-52, tradução nossa). ${ }^{5}$

Nesse ambiente, a estratégia de um Estado passa a depender "de como se dá sua interação, ou combinação, com as estratégias dos demais atores (...) [sendo] preciso calcular suas chances considerando variáveis que ele não controle: as decisões de outros atores" (NOGUEIRA; MESSARI; 2005, p. 91-92). Assim, a interdependência no sistema internacional torna o cumprimento de objetivos individuais mais difícil, senão pela cooperação e ajuste de postura.

A liderança do Brasil na Minustah apresenta um novo paradigma da política externa brasileira sob as rédeas de Lula da Silva. O Estado logístico, consolidado a partir de 2003, fez com que o país tomasse consciência do papel do Estado ao requisitar ações políticas para que a nação penetrasse processos globais como agente ativo do sistema de que faz parte (CERVO, 2012). Portanto, o comando de uma operação de relevo internacional emerge da busca do Brasil em projetar-se internacional e regionalmente, "ampliando, principalmente, sua legitimidade na região sul e latino-americana" (FERREIRA, 2012, p. 3).

A diplomacia brasileira encontrou suporte em três elementos para a consolidação do chamado Estado logístico: 1) existência de estabilidade política e econômica, (2) organizações articuladas entre si dentro da sociedade, que facilitaram a função de coordenação superior do Estado e do seu interesse nacional; e (3) nível avançado de organização e competitividade dos agentes econômicos e sociais (CERVO; BUENO, 2012). A estabilidade e a coordenação internas somadas aos esforços do governo em adquirir proeminência externa possibilitaram sua consolidação entre as dez principais economias do planeta e a construção da imagem de país emergente e dinâmico, pois o Brasil se tornou um ator necessário em debates multilaterais (WIKILEAKS, 2008).

Ao servirem como sustentadores do sistema internacional por meio do multilateralismo e da boa governança, potências emergentes como o Brasil entenderam

\footnotetext{
${ }^{5}$ Cooperation occurs when actors adjust their behavior to the actual or anticipated preferences of others, through a process of policy coordination. To summarize more formally, intergovernmental cooperation takes place when the policies actually followed by one government are regarded by its partners as facilitating realization of their own objectives, as the result of a process of policy coordination.
} 
que são necessárias reformas das estruturas de poder para alcançar maior projeção nesse cenário (KENKEL; MORAES, 2012). O multilateralismo é, então, utilizado como "meio ou instrumento [...] para projetar influência no plano internacional e fazer valer o que seus agentes diplomáticos definiram como interesse nacional” (NASSER, 2012, p. 225).

Visando a uma participação ativa nesse ambiente, o Brasil busca "o reforço de poder para influir sobre o ordenamento global e os regimes setoriais" (CERVO; BUENO, 2012, p. 528). Assim, a política externa brasileira ocorre por meio do que Cervo e Bueno (2012) caracterizam como multilateralismo da reciprocidade, cujo pressuposto admite que a existência e a elaboração de regras no ordenamento internacional devem garantir tratamento proporcional a todos os agentes.

Na busca por maior relevância, o Brasil tornou-se um dos principais entusiastas da reforma de organizações internacionais a partir dos anos 2000. Mudanças na composição do CS estão entre as principais demandas nacionais, uma vez que, juntamente com o Japão, o Brasil é o país que mais vezes ocupou um assento não permanente. Entre 2003 e 2014, o país demandou reformas na composição do CS por 12 vezes ao abrir a Assembleia Geral das Nações Unidas (AG).

A ausência de renovação no quadro de membros permanentes com direito a veto e a inexistência de representação de países em desenvolvimento entre os membros permanentes colocam em cheque a legitimidade e a eficácia de uma instituição que ainda reflete o cenário pós-Segunda Guerra Mundial, cujos vencedores tornaram-se responsáveis por decisões de caráter global (MRE, 2015). Além disso, o CS passa a ser visto como um órgão com pouca representatividade devido às mudanças ocorridas no cenário internacional e no aumento do número de Estados-membros das Nações Unidas de 51 para 193 (UN, 2011a).

Em consonância com essa demanda, o Brasil tornou-se um país que não se limita a apenas apresentar aparência de potência emergente, mas busca agir de tal modo, adotando práticas e responsabilidades à altura de seus anseios (CERVO; LESSA, 2014). Isso indica que as missões de paz demonstram a existência de uma estreita relação entre o ativismo pela renovação do CS e a participação do Brasil em missões de paz, especialmente a Minustah. 
O uso de poderio militar como um instrumento da política externa brasileira é, para Alsina Jr. (2009), um indício de que mudanças qualitativas na política de defesa podem proporcionar maior alcance na atuação de um país desde que ele consiga coordenar adequadamente matérias militares e diplomáticas. Isso é resultado do entendimento de que a maneira mais rápida de alcançar um perfil estratégico relevante é desenvolver uma "expressão militar do poder e demonstrar a inclinação de colocá-la à disposição dos esforços da comunidade internacional para resolver conflitos, mitigar catástrofes humanitárias e salvaguardar os direitos humanos" (KENKEL; MORAES, 2012, p. 11).

O comando da Minustah "atende o interesse nacional como forma de projeção de poder e influência do país no cenário internacional no longo prazo (...) [e] eleva as credenciais de um país junto aos demais membros da comunidade internacional" (NASSER, 2012, p. 226). Assim, as instituições internacionais, como no caso do CS, têm a capacidade de influenciar "as ações estatais na medida em que [estas] afetam seus incentivos e custos e [...] ajudam na compreensão do papel, dos interesses e das motivações dos Estados" (NOGUEIRA; MESSARI, 2005, p. 96-97).

Nessa acepção, para o embaixador Antônio de Aguiar Patriota, o comando das tropas e a disposição em levar paz e desenvolvimento e auxiliar na redemocratização do Haiti são uma forma de exprimir compromisso com o multilateralismo e com os anseios de assumir responsabilidades internacionais mais relevantes (KENKEL; MORAES, 2012). Valler Filho (2007) alega que o discurso da diplomacia brasileira oficializa a postura de um país disposto a oferecer cooperação, na condição de parceiro para o desenvolvimento, sem a qual o país não conseguiria trazer seus objetivos à existência com a mesma eficiência.

A diplomacia solidária representa o desejo nacional de afirmar-se como potência emergente e criou a necessidade de o país demonstrar resultados concretos para a comunidade internacional. De fato, o uso da palavra solidariedade surge para justificar uma decisão política de utilizar a liderança da Minustah como projeção internacional, elemento favorável à "aceitação do Brasil como um novo membro permanente do Conselho de Segurança" (ALMEIDA, 2011).

Essa também era a percepção dos Estados Unidos em documentos confidenciais de sua embaixada em Brasília, divulgados pelo WikiLeaks (2008), nos quais o Brasil 
permanecia comprometido com a Minustah visando qualificar-se a um assento no CS. Um ano depois, o WikiLeaks (2009) traria à tona mais um documento cujo entendimento da aspiração do Brasil a um assento no CS fora considerado prioridade máxima da política externa brasileira.

Os governos Lula da Silva e Dilma Rousseff, entre 2003 e 2014, mantiveram-se alinhados, tanto no discurso quanto na prática, a respeito da demanda por um assento permanente no CS e da participação em operações de paz. Das 17 missões de paz da ONU em operação no ano de 2014, o Brasil esteve presente militarmente em dez (58\%). Dentre essas, sete operações haviam sido estabelecidas no período de governo de Lula da Silva ou Rousseff (2003-2014), o que significa 70\% dentre aquelas em que o país mantinha tropas.

Esses números são mais relevantes se comparados com o período que abrange os anos de 1990 a 2002, quando o Brasil participou de apenas 23 das 48 missões, uma recusa de aproximadamente 52\% (UN, 2015b, 2015d, 2015e). Enquanto ocupou assento não permanente no CS nos governos de Lula da Silva e Rousseff, o Brasil participou de seis das sete operações de paz das Nações Unidas (86\%). A mesma análise cabe para o último decênio do século XX (1993-94 e 1998-99), quando houve 15 missões de paz e o Brasil participou de apenas quatro, uma recusa de 68\% (UN, 2015b, 2015d, 2015e).

Por meio desses dados é possível admitir que a solidariedade brasileira, embora louvável, não significa nem representa filantropia desinteressada. Os formuladores da política externa brasileira parecem coadunar um projeto de inserção nacional e o auxílio às nações menos favorecidas de modo que, "mais que coexistir, a projeção de poder e a solidariedade amalgamaram-se na maneira como o Brasil escolheu se inserir no mundo" (NASSER, 2012, p. 226).

A existência de apoio recíproco entre agentes locais e autóctones parece ser condição sine quae non para que os agentes logrem êxito em seus objetivos. Se, por um lado, o Brasil consegue resultados com a Minustah em elementos de caráter secundário, sua aspiração a um assento permanente no CS não parece ter o mesmo alcance. Para Cervo e Lessa (2014), há um declínio e deterioração de elementos que indicam a presença e a influência do Brasil no cenário internacional, como é o caso da economia, da política e da geopolítica. Como explica Bobbio, embora a "possibilidade de recorrer à força seja o 
elemento que distingue o poder político das outras formas de poder, não significa que o poder político se resuma ao uso da força" (2000, p. 164).

A força militar dispensada pelo Brasil em sua projeção internacional parece ser uma condição necessária para a influência de seu poder político nesse ambiente. A Minustah traz resultados que extrapolam os limites haitianos, mas também demonstra que essa não é condição única e suficiente para o país alcançar o almejado posto de membro permanente do CS.

\section{CONSIDERAÇÕES FINAIS}

A tradição do Brasil como entusiasta da paz, desenvolvida desde suas primeiras participações em operações de paz das Nações Unidas, já na primeira década de existência dessa instituição, e oficializada em 1988 por sua Carta Magna, tem seu auge com o comando da Minustah, a partir de 2004. Uma vez alcançada estabilidade política e econômica no ambiente interno durante o governo de Lula da Silva, verifica-se uma ênfase no aspecto militar como forma de expressão de poder e influência no sistema internacional.

Diferentemente das operações alocadas no Haiti que pautaram sua atuação exclusivamente no caráter militar durante a década de 1990, a Minustah é uma missão multidisciplinar que busca promover, além da segurança e da estabilidade do país, um processo político-democrático e os direitos humanos da população. Com a atuação da Minustah, não é possível verificar mudanças significativas nos índices de Desenvolvimento Humano e de Estados Falidos. Não há um crescimento expressivo e/ou constante do Produto Interno Bruto do Haiti, que é frequentemente prejudicado por eventos pontuais. A diminuição das tropas empregadas na missão em 2014 para números semelhantes aos de 2004 não promove indícios de uma retirada total da missão.

A inexistência de uma data para o término e a retirada da missão e a interdependência estabelecida entre ela e o Estado haitiano são indicativos de que a Minustah peca na transição do poder para os agentes autóctones. Percebe-se assim a existência de uma relação de interdependência entre a legitimação do governo nacional e a presença da Minustah em solo haitiano. Não obstante, os resultados logrados nos dez 
primeiros anos de existência da operação esbarram na falta de vontade política para mudar e atuam como meros paliativos de recorrentes desastres naturais.

A opção do Brasil por tomar a frente da Minustah sinaliza uma mudança em sua estratégia de inserção e consolidação no sistema internacional por meio do multilateralismo de reciprocidade. Essa mudança justifica-se pela postura humanista do presidente Lula da Silva, pelos conceitos de diplomacia solidária e não indiferença e pela continuidade dada a isso no primeiro mandato de Dilma Rousseff. Embora o empenho brasileiro no Haiti seja louvável, essa missão não significa filantropia desinteressada, uma vez que a projeção de poder e a solidariedade tornaram-se uma das estratégias legítimas para sua inserção e consolidação como potência.

A força militar empregada pelo Brasil no Haiti, a fim de projetar-se internacionalmente, tornou-se uma das estratégias para maior influência de seu poder político. Apesar disso, o declínio e a deterioração política e econômica durante o governo Rousseff demonstram que pautar a política externa exclusivamente em esforços militares é insuficiente para a inserção e a consolidação internacionais.

\section{REFERÊNCIAS}

ALMEIDA, Paulo Roberto de. O Brasil no Haiti: uma visão pessoal - PRA. 2011. Disponível em: $\quad$ http://diplomatizzando.blogspot.com.br/2012/07/o-brasil-no-haiti-umavisao-pessoal-pra.html>. Acesso em: 11/05/2015.

ALSINA JR, João Paulo Soares. O poder militar como instrumento da política externa brasileira contemporânea. Rev. bras. polít. int. [online]. 2009, vol.52, n.2, pp. 173-191.

BOBBI0, Norberto. Teoria Geral da Política - a filosofia política e as lições dos clássicos. Coletânea organizada por Michelangelo Bovero. Tradução de Daniela Beccaccia Versiani. Rio de Janeiro : Campus, 2000.

BORGES, Elaine. A missão de paz no Haiti (MINUSTAH) e a reconstrução da imagem do Exército brasileiro pós-redemocratização. 146f. Dissertação (Mestrado em Sociologia Política) - Universidade Estadual do Norte Fluminense Darcy Ribeiro. Campo dos Goytacazes, 2011. Disponível em: < http://uenf.br/pos-graduacao/sociologiapolitica/files/2013/03/Disserta\%C3\%A7\%C3\%A3o-Elaine-vers\%C3\%A3o-finalpdf.pdf>. Acesso em: 05/05/2015.

BRACEY, Djuan. O Brasil e as operações de manutenção da paz da ONU: os casos do Timor Leste e Haiti. Contexto Internacional, Rio de Janeiro, v. 33, n. 2, 2011.

CERVO, Amado Luiz. O Brasil na atual ordem mundial. Austral: Revista Brasileira de Estratégia e Relações Internacionais, Porto Alegre, v.1, n.2, Jul-Dez, 2012. p.37-59. Disponível em: 
http://www.seer.ufrgs.br/austral/article/viewFile/30514/20485>. Acesso em: $30 / 04 / 2015$.

. Inserção Internacional: formação dos conceitos brasileiros. São Paulo : Saraiva, 2008.

CERVO, Amado Luiz; BUENO, Clodoaldo. História da política exterior do Brasil. 4 ed. Ver. Ampl., 1aㅡ reimp. Brasília : Editora Universidade de Brasília, 2012.

CERVO, Amado Luiz; LESSA, Antônio Carlos. O declínio: inserção internacional do Brasil (2011-2014). Rev. Bras. Polít. Int. 57 (2). 2014. p. 133-151. Disponível em: <http://www.scielo.br/pdf/rbpi/v57n2/0034-7329-rbpi-57-02-00133.pdf>. Acesso em: 10/05/2015.

DEFESA. EXÉRCITO BRASILEIRO. Missões de Paz. Disponível em: <http://www.eb.mil.br/missoes-de-paz/>. Acesso em: 16/02/2015.

FADISMA - Faculdade de Direito de Santa Maria. FADISMA oferece denúncia contra a ONU. Santa Maria, 13 dez. 2011. Central de Notícias. Disponível em: <http://fadisma.com.br/noticias/fadisma-oferece-denuncia-contra-a-onu-884/>. Acesso em: 07/04/2015.

FAGANELLO, Priscila Liane Fett. Operações de manutenção da paz da ONU: de que forma os direitos humanos revolucionaram a principal ferramenta internacional da paz. Brasília : FUNAG, 2013.

FERREIRA, Carlos Enrique Ruiz. O Brasil enquanto membro não permanente no Conselho de Segurança das Nações Unidas no mandato 2010-2011. Programa de Cooperación em Seguridad Regional. 2012. Disponível em: <http://library.fes.de/pdffiles/bueros/la-seguridad/09107.pdf>. 22/09/2014.

FFP - The Failed State Index. 2008. Disponível em: <http://fsi.fundforpeace.org/rankings2008-sortable>. Acesso em: 09/03/2015.

GAUTHIER, Amelie; SOUSA, Sarah. Brazil in Haiti: debate over the peacekeeping mission. Fundación para las Relaciones Internacionales y Del Dialogo Exterior, 2006. Disponível em: <http://www.fride.org/eng/File/ViewFile.aspx?FileId =1193>. Acesso em: 07/05/2015.

GoH - Government of Haiti. Action Plan for National Recovery and Development of Haiti. 2010. Disponível em: <http://www.haitireconstructionfund.org/system/files/Haiti\%20Action\%20Plan.p df>. Acesso em: 24/03/2015.

GONZALEZ, Elizabeth. 2014 Election Blog: Haiti's October Legislative Elections in Doubt. Americas Society/Council of the Americas. 15 jul. 2014. Disponível em: <http://www.as-coa.org/blogs/2014-election-blog-haitis-october-legislativeelections-doubt>. Acesso em: 15/04/215.

GS - GlobalSecurity. Rene Préval (2006-2010). 2011. Disponível em: <http://www.globalsecurity.org/military/world/haiti/politics-preval-2006.htm>. Acesso em: 03/03/2015.

HDR - Human Development Report. Disponível em: <http://hdr.undp.org/ >. Acesso em: 05/02/2015. 
HRW - Human Rights Watch. World Report. 2015. Disponível em: <http://www.hrw.org/world-report/2015/country-chapters/haiti>. Acesso em: 23/04/2015.

IHSI - Institut Haïtien de Statistique et d'Information. Disponível em: <http://www.ihsi.ht/>. Acesso em: 09/04/2015.

IMMHE - INTERNATIONAL MISSION FOR MONITORING HAITIAN ELECTIONS. Final Report on the December 3, 2006, Elections. 2007. Disponível em: <http://www.mieehimmhe.ca/report_dec06_e.html>. Acesso em: 10/03/2015.

IPU - INTER-PARLIAMENTARY UNION. IPU PARLINE database: HAITI (Sénat), Full text. 2015. Disponível em: <http://www.ipu.org/parlinee/reports/2138.htm>. Acesso em: 26/02/2015.

. IPU PARLINE database: HAITI (Sénat) ELECTIONS IN 2009. 2010. Disponível em: <http://www.ipu.org/parlinee/reports/arc/2138_09.htm>. Acesso em: 26/02/2015

. IPU PARLINE database: HAITI (Sénat), Elections in 2006. Disponível em <http://www.ipu.org/parlinee/reports/arc/2138_06.htm>. Acesso em: 26/02/2015.

KEOHANE, Robert Owen. After Hegemony: Cooperation and Discord in the World Political Economy. New Jersey : Princeton University Press, 1984

KENKEL, Kai Michael; MORAES, Rodrigo Fracalossi de (Orgs.). 0 Brasil e as operações de paz em um mundo globalizado: entre a tradição e a inovação. Brasília: IPEA, 2012.

LANZONI, Ilaria. Five Years After 2010 Earthquake, Thousands of Haitians Remain Displaced. International Organization for Migration, Suíça, 09 jan. 2015. Disponível em: <https://www.iom.int/cms/en/sites/iom/home/news-and-views/pressbriefing-notes/pbn-2015/pbn-listing/five-years-after-2010-earthquake.html>. Acesso em: 23/04/2015.

LFH - Lessons from Haiti. Key Statistics. Disponível em: <http://www.lessonsfromhaiti.org/lessons-from-haiti/key-statistics/>. Acesso em: 20/03/2015.

MARINHA. Marinha do Brasil nas Operações de Paz: Força Tarefa Marítima UNIFIL. Disponível em: <https://www.mar.mil.br/hotsites/operacao_paz/unifil/unifil.html>. Acesso em: $20 / 02 / 2015$.

MONTES, Juan Esteban; FELDMANN, Andreas; PIRACÉS, Sandra. Haití: Huracanas en un Año de Calma. Revista de Ciência Política. v. 29, n.2, 2009. Disponível em: <http://www.revistacienciapolitica.cl/2013/articulos/haiti-huracanes-en-un-anode-calma/>. Acesso em: 07/04/2015.

MRE. MINISTÉRIO DAS RELAÇÕES EXTERIORES. Reformando o Conselho de Segurança das Nações Unidas. Disponível em: <http://csnu.itamaraty.gov.br/glossario>. Acesso em: $12 / 02 / 2015$.

NASSER, Filipe. Pax brasiliensis: projeção de poder e solidariedade na Estratégia diplomática de participação brasileira em Operações de paz da organização das nações unidas. In: KENKEL, Kai Michael; MORAES, Rodrigo Fracalossi de (Orgs.). 0 Brasil e as operações de paz em um mundo globalizado: entre a tradição e a inovação. Brasília: IPEA, 2012.p. 213-242 
NOGUEIRA, João Pontes; MESSARI, Nizar. Teoria das Relações Internacionais: correntes e debates. Rio de Janeiro : Elsevier, 2005. 7ª reimp.

OELSNER, Andrea. Consensus and Governance in Mercosur: The Evolution of the South American Security Agenda. In: ARIS, Stephen; WENGER, Andreas. Regional Organisations and Security: Conceptions and practices. New York : Routledge, 2014.

PROJET 16/6. Factsheet December 2012. 2012. Disponível em: <http://www.projet166.org/factsheet/Factsheet_December_2012.pdf>. Acesso em: 10/04/2015.

PUFF, Jefferson. Diretor da ONU quer Brasil em mais missões internacionais de paz. BBC, Rio de Janeiro, 31 mai. 2014. Brasil. Disponível em: <http://www.bbc.co.uk/portuguese/noticias/2014/05/140531_onu_brasil_missoes _paz_jp_an>. Acesso em: 20/02/2015.

RESERVE, Roody. Haití: Cuando el Pasado es Demasiado Pesado. Rev. cienc. polít., Santiago, v. 33, n. 1, 2013 . Disponível em: <http://www.scielo.cl/scielo.php?script=sci_arttext\&pid=S0718090X2013000100011\&lng=es\&nrm=iso>. Acesso em: 08/04/ 2015.

SCR - Security Council Report. Chronology of Events: Haiti. 2015. Disponível em: <http://www.securitycouncilreport.org/chronology/haiti.php?page=1>. Acesso em: $04 / 03 / 2015$.

SEITENFUS, Ricardo Antônio da Silva; ZANELLA, Cristine Koehler; MARQUES, Pâmela Marconatto. O Direito Internacional repensado em tempos de ausências e emergências: a busca de uma tradução para o princípio da não-indiferença. Revista Brasileira de Política Internacional. 2007, vol. 50, n.2.

SEITENFUS, Ricardo Antônio da Silva. Haiti : Dilemas e fracassos internacionais. Ijuí : Ed. Unijuí, 2014a.

Elementos para uma diplomacia solidária: a crise haitiana e os desafios da ordem internacional contemporânea, Carta Internacional. São Paulo: Nupri-USP, vol. 1, no 1 , mar. 2006, p. 5-12. Disponível em : <link http://www.usp.br/cartainternacional/ $\operatorname{modx} /$ assets/docs/CartaInter_2006-01.pdf>. Acesso em: 06/05/2015.

SOUZA NETO, Danilo Marcondes de. O Brasil, o Haiti e a MINUSTAH. In: KENKEL, Kai Michael; MORAES, Rodrigo Fracalossi de (Orgs.). 0 Brasil e as operações de paz em um mundo globalizado: entre a tradição e a inovação. Brasília: IPEA, 2012. p. 243-268

UN - UNITED NATIONS. Conduct and Discipline Unit. Statistics: Allegations by Category of Personnel Per Mission (Sexual Exploitation and Abuse). 2015a. Disponível em: $<$ https://cdu.unlb.org/Statistics/AllegationsbyCategoryofPersonnelSexualExploitati onandAbuse/AllegationsbyCategoryofPersonnelPerMissionSexualExploitationandA buse.aspx>. Acesso em: 07/04/2015.

Current Peacekeeping Operations. 2015b. Disponível em: <http://www.un.org/en/peacekeeping/operations/current.shtml>. Acesso em: 20/02/2015.

. ECOSOC: Report of the Ad Hoc Advisory Group on Haiti E/2013/90. Geneva, 5 jul. 2013a. <http://www.un.org/ga/search/view_doc.asp?symbol=E/2013/90>. Acesso em: $17 / 04 / 2015$. 
Haiti Cholera Response. November 2014. 2014a. Disponível em: <http://www.onu-haiti.org/wp-content/uploads/2014/12/UN-Factsheet-FinalVersionCholera-October-November-2014.pdf>. Acesso em: 23/04/2015.

Member States. Growth in United Nations membership, 1945-present. 2011a. Disponível em: <http://www.un.org/en/members/growth.shtml>. Acesso em: $10 / 05 / 2015$.

. MINUSTAH. United Nations Stabilization Mission in Haiti. 2015c. Disponível em: <http://www.un.org/en/peacekeeping/missions/minustah/>. Acesso em: $25 / 02 / 2015$.

. MINUSTAH. Note d'information: Opération conjointe MINUSTAH-PNH à Bellecourt [FR/EN]. Porto Príncipe, 02 de julho de 2014. 2014b. Disponível em: <http://www.minustah.org/note-dinformation-operation-conjointe-minustah-pnha-bellecourt-fren/>. Acesso em: 29/05/2016.

Past Peacekeeping operations. 2015d. Disponível em: <http://www.un.org/en/peacekeeping/operations/past.shtml>. Acesso em: 20/02/2015.

Presidential Elections. 2011b. Disponível em: <http://www.un.org/en/peacekeeping/missions/minustah/elections.shtml>. Acesso em: 25/03/2015.

. Security Council Resolution 1529 (2004). 2004a. Disponível em: <http://www.un.org/en/ga/search/view_doc.asp?symbol=S/RES/1529(2004)>. Acesso em: 12/03/2015.

. Security Council Resolution 1542 (2004). 2004b. Disponível em: <http://www.un.org/en/ga/search/view_doc.asp?symbol=S/RES/1542(2004)>. Acesso em: 12/03/2015.

Security Council Resolution 1576 (2004). 2004c. Disponível em: <http://www.un.org/en/ga/search/view_doc.asp?symbol=S/RES/1576(2004)>. Acesso em: 12/03/2015.

. Security Council Resolution 1908 (2010). 2010a. Disponível em: <http://www.un.org/en/ga/search/view_doc.asp?symbol=S/RES/1908(2010)>. Acesso em: 20/03/2015.

. Security Council Resolution 1927 (2010). 2010b. Disponível em: <http://www.un.org/en/ga/search/view_doc.asp?symbol=S/RES/1927(2010)>. Acesso em: 20/03/2015.

. Security Council Resolution 1944 (2010). 2010c. Disponível em: <http://www.un.org/en/ga/search/view_doc.asp?symbol=S/RES/1944(2010)>. Acesso em: 20/03/2015.

Security Council Resolution 2070(2012). 2012a. Disponível em: <http://www.un.org/en/ga/search/view_doc.asp?symbol=S/RES/2070(2012)>. Acesso em: 08/04/2015.

__ Security Council Resolution 2119(2013). 2013b. Disponível em: <http://www.un.org/en/ga/search/view_doc.asp?symbol=S/RES/2119(2013)>. Acesso em: 17/04/2015. 
Troop and police contributors to United Nations Peacekeeping Operations. 2015e. Disponível em: <http://www.un.org/en/peacekeeping/resources/statistics/contributors.shtml>. Acesso em: 20/02/2015.

UN FACT SHEET: Combating Cholera in Haiti. 2014b. Disponível em: <http://www.un.org/News/dh/infocus/haiti/Cholera_UN_Factsheet_24\%20Feb_20 14.pdf>. Acesso em: 17/04/2015.

United Nations Documents on MINUSTAH: Resolutions of the Security Council. $2015 f$.

Disponível

em:

<http://www.un.org/en/peacekeeping/missions/minustah/resolutions.shtml>. Acesso em: 31/03/2015.

United Nations Mission in Haiti. 2003. Disponível em: <http://www.un.org/en/peacekeeping/missions/past/unmih.htm>. Acesso em: $24 / 02 / 2015$.

VALLER FILHO, Wladimir. O Brasil e a crise haitiana: a cooperação técnica como instrumento de solidariedade e de ação diplomática. Brasília : FUNAG, 2007.

WIKILEAKS. Scenesetter For The December 13-14 Visit Of Wha. Reference ID: 09BRASILIA1411, 10/12/2009. Disponível em: <https://wikileaks.org/cable/2009/12/09BRASILIA1411.html>. Acesso em: $11 / 05 / 2015$.

. Scene setter for the visit of minister of defense Nelson Jobim to Washington. Reference ID: 08BRASILIA351, 13/03/2008. Disponível em: <http://wikileaks.ch/cable/2008/03/08BRASILIA351.html>. Acesso em: $04 / 02 / 2015$. 